\title{
Arquitectura militar en las villas medievales del Arzobispo de Toledo: función y significado
}

\author{
Magdalena Merlos *
}

\begin{abstract}
RESUMEN ABSTRACT
La arquitectura militar de las villas del arzobispo de Toledo está representada por dos tipos de construcciones: el castillo y la cerca.

Su función, significado e interrelaciones sobre la trama urbana se abordan desde el marco histórico del señorío medieval.

There are two types of military architecture in the towns of the archbishop of Toledo: the castle and the surrounding wall. This article deals with their function, significance and relationship to the urban plan, taking into account the historical context of the medieval fuedal estate.
\end{abstract}

El señorío medieval del arzobispo de Toledo tiene su punto de partida en la expansión territorial y repobladora de la Corona de Castilla, y en el decidido apoyo que la Mitra proporciona a sus reyes en este proceso. En correspondencia, los reyes protegerán a la institución eclesiástica ${ }^{1}$. Las prerrogativas señoriales, donaciones y privilegios que el arzobispo de Toledo recibe de la Corona, lo convierten no sólo en un señor feudal, sino en la figura más poderosa de la Castilla Medieval tras el rey.

El mapa señorial del arzobispo de Toledo se traza en la línea del Tajo Medio y sus afluentes, a excepción de la avanzada fronteriza del

* UNED. Departamento de Historia del Arte. Tercer Ciclo.

Entre otras medidas se designa al arzobispo de Toledo Primado de España y Canciller Real (ésta concedida en 1206, julio, 1 al arzobispo Martín López de Pisuerga y a sus sucesores). J.F. Rivera Recio, La Iglesia de Toledo en el siglo xil (1086-1208). Roma, 1966, Toledo 1983. 2 vol., vol. I, pág. 241; F.J. HeRnández, Los Cartularios de Toledo. Madrid, 1985, doc n. ${ }^{\circ}$ 288. 
Adelantamiento de Cazorla ${ }^{2}$. Este mapa responde a un interés estratégico, no sólo económico y comercial, sino especialmente social y político.

La base de organización administrativa y política será la comunidad de tierra y villa. La villa, cabeza de un territorio, se desarrolla en el marco legal del fuero, donde el arzobispo como señor reglamenta el gobierno, la actividad económica, el sistema impositivo, la organización de gremios y colectivos, y determina en última instancia la estructura funcional del asentamiento. Ello se traduce en la definición de un modelo de urbanismo, donde la cerca urbana será el elemento que identifica a la villa como un espacio cerrado, acotado, contrapuesto al resto del territorio.

La historia y evolución del patrimonio de la Mesa Arzobispal se inicia con la dote fundacional de 1086 que Alfonso VI da a la Iglesia de Toledo ${ }^{3}$. Un nutrido grupo de las poblaciones que recibe ahora (Almonacid y Brihuega) y a partir de este momento, alcanzarán el rango de villa en la segunda mitad del siglo XII y principalmente en la primera del XIII ${ }^{4}$.

Durante el siglo XII, coincidiendo con una segunda fase de repoblación se incorporan Alcalá (1129 ${ }^{5}$ ), Belinchón (1146, con fuero de $1171^{6}$ ), Esquivias $\left(1188^{7}\right.$ ) y Talamanca $\left(1188^{8}\right)$.

La nómina de villas conoce un interesante incremento durante el siglo XIII, consecuencia de la estabilidad de la cuenca del Tajo, definitivamente alejada de la línea de frontera. En la época de Rodrigo Jiménez de Rada,

2 M.M. García GuzmÁn, El adelantamiento de Cazorla en la Baja Edad Media. Un señorío eclesiástico en la frontera castellana. Cádiz, 1985. El arzobispo D. Juan recibe las primeras donaciones del futuro adelantamiento de Cazorla a partir de 1156, aunque la conformación del Adelantamiento es efectiva con la definitiva incorporación de la zona a Castilla durante el siglo XIII.

3 Archivo Capitular de Toledo (O.2.N.1.1v); A. GonzÁlez PALENCIA, Los mozárabes de Toledo en los siglos XII y XII. Madrid, 1930. 4 vol., vol. prel. págs. 155-157; J.F. Rivera Recio, La iglesia..., pág. 70-71. pág. 97 transcribe el texto; F.J. Hernández, Los Cartularios..., doc n. ${ }^{\circ}$; J. A. Garcia LUJÁ, Privilegios reales de la catedral de Toledo (1086-1462). Granada, 1982. 2 vol. doc n. ${ }^{\circ}$. La Mesa Arzobispal se desliga de la Capitular a partir de 1138.

4 Hemos simplificado el proceso, ya presentado en nuestra Memoria de Licenciatura (UNED, 1995), para reducirlo sólo a los lugares que son villa antes o después.

5 ACT. A. 3. A. 1. 1 y 1 a, 1b.; F. FITA, «Bula inédita de Honorio II», BRAH VII (1885) págs. 335-339; F.J. HERNÁNDEZ, LOS Cartularios, doC n. ${ }^{\circ} 29$. Sobre la datación exacta, y el estudio pormenorizado del documento, vid M.J. VÁzQUEz MADRUGA, "La donación de Alcalá a los arzobispos de Toledo. Institución del señorío de Alcalá. Documento fundacional», Alcalá 1293: una villa universitaria de la Edad Media, Alcalá de Henares, 1993, págs. 49-57.

6 ACT A.10.E.1.2; J.F. Rivera RECIO, La lglesia...l, pág. 37 y il págs. 72, 80, 85; F.J. Hernández, Los Cartularios..., doc n. ${ }^{\circ} 57$; J.A. Garcla Luján, Op. cit., doc n. ${ }^{\circ} 17$.

7 1188, febrero, 13. ACT O.1.E.1.1 (donación de todas las propiedades de Alfonso VIII en lliescas y Esquivias a Gonzalo Pérez). J. GonzÁlez, El reino de Castilla en la época de Alfonso VIII. Madrid, 1960. 2 vols., doc n. 491.

81188 , febrero, 12. J. GonZÁlez, El reino..., doc n. ${ }^{\circ} 490$. 


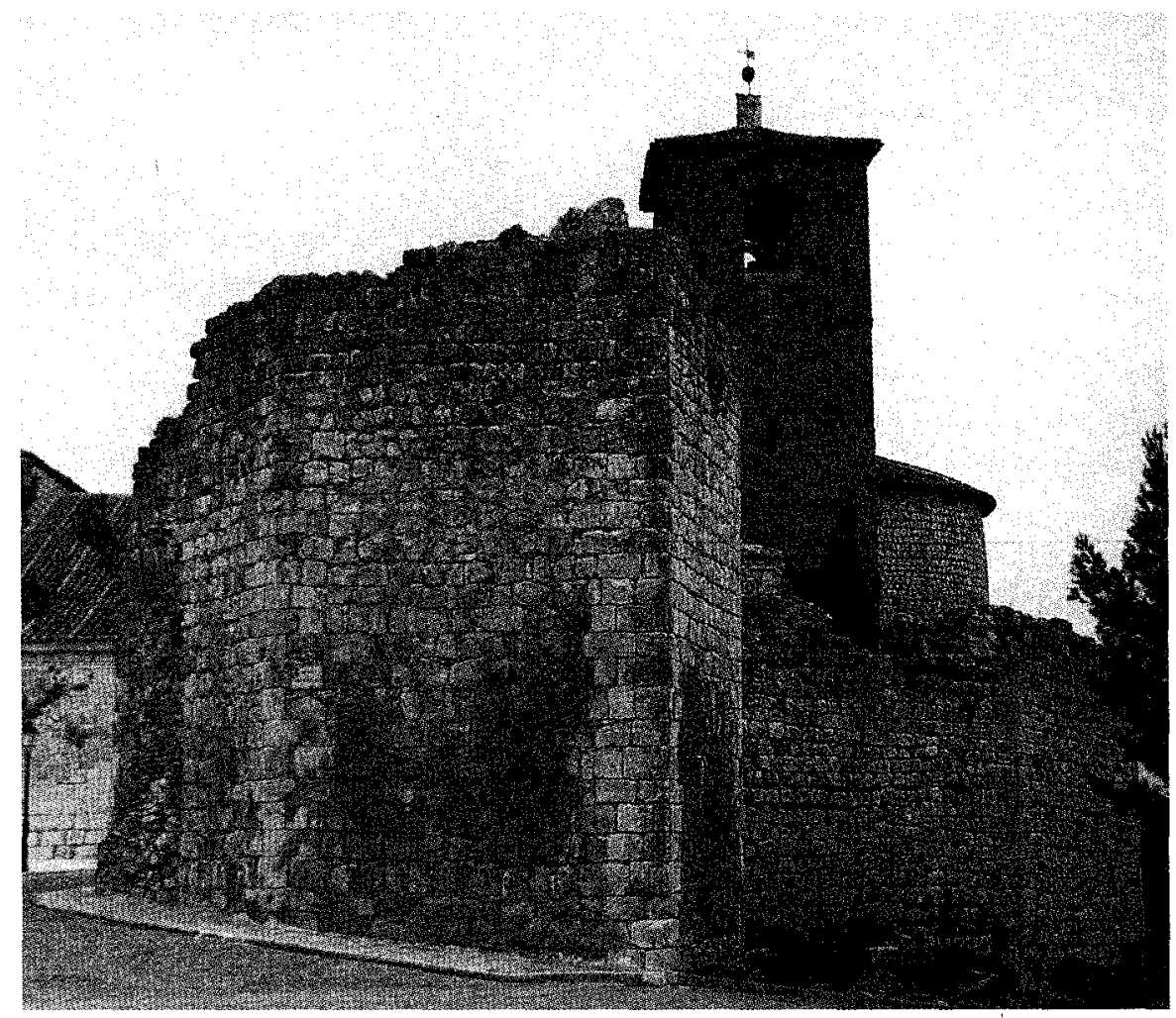

Fig. 1. Vista del primer recinto de Santorcaz.

y al sur del Tajo, se incorporan el castillo de Bogas $\left(1211^{9}\right.$, en cuyas inmediaciones se formará Villanueva de Bogas), Yepes (adquisiciones entre 1213-1215 ${ }^{10}$ ), La Guardia (entre 1213 y 1218), Lillo y El Romeral $\left(1228^{11}\right)$.

9 F.J. HeRnÁNDEZ, Los Cartularios..., doc n. 323.

10 1213, agosto, 22. ACT O.10.B.1.1; BN Ms. 13034 fol. 204; Col. Salazar y Castro C-15 fol. 150; J. GonzÁlez, El reino..., doc n. 911; A. GonzÁlez PALEnCIA, Los mozárabes..., vol. prel., pág. 99; E. Estella, El fundador de la catedral de Toledo. Estudio histórico del pontificado de $D$. RODRIGo JIMÉNEZ DE RADA en la sede toledana. Toledo, 1926; M. MERLOS Romero, Yepes en la Edad Media. Población, urbanismo, arquitectura. Toledo, 1998. Copia del fuero en Biblioteca Nacional (BN). Ms. 897, fol. 29g.

11 F.J. HeRnÁndez, Los Cartularios..., doc. n. ${ }^{\circ}$ 423. Referencias a Lillo como villa en 1435 (E. Benito Ruano, "Visita de las villa y lugares del arzobispado de Toledo (1435)», Anales Toledanos, $\checkmark$ (1971), págs. 77-104). 
En 1214 se confirma el testamento de Alfonso VIII ${ }^{12}$, mediante el cual a la Mesa Arzobispal se incorporan Torrijos ${ }^{13}$ y parte de Esquivias ${ }^{14}$, poblaciones al Norte del Tajo. A ellas se suma Añover en $1243^{15}$.

Los años centrales del siglo XIII conocen las donaciones de Alfonso XI a su hermano el arzobispo D. Sancho el Electo (1250-1261) en el entorno de Alcalá de Henares y Brihuega: Uceda ${ }^{16}$ en 1252 (una de sus aideas, Torrelaguna será villa desde $1390{ }^{17}$ ) y Fuentes e Hita en $1255^{18}$.

Queda así constituido el señorío del arzobispo de Toledo a mediados del siglo XIII. No conocerá importantes modificaciones hasta el último cuarto del siglo XIV, con la llegada de la dinastía Trastámara. El arzobispo será uno de los beneficiarios de las mercedes enriqueñas. En 1369 recibe Talavera ${ }^{19}$, Illescas y Azaña ${ }^{20}$. El interés por la región talaverana y su conexión con Guadalupe explica la fundación por parte de Pedro Tenorio de la Villafranca de la Puente del Arzobispo (1390) ${ }^{21}$, en el territorio de

12 1214, noviembre, 8. Confirmación de Enrique I del testamento de Alfonso VIII que incluye la donación a la Catedral de Toledo de la aldea de Torrijos y una parte de Esquivias (J. GonZÁLEZ, El reino..., doc n. ${ }^{\circ} 969$; J.A. Garcia LUJÁN, Op. cit., doc n. ${ }^{\circ} 50$; F.J. HeRnández, Los Cartularios..., doc n. 356). En 1236, octubre, 29 la mesa capitular reclamará las posesiones de Esquivias, Torrijos y la apoteca de Talavera (F. FITA, "La Guardia, villa del partido de Lillo, provincia de Toledo. Datos históricos», BRAHXI (1887), pág. 400.

13 Adquirida como aldea, posteriormente alcanza el rango de villa. En 1482 será vendida por el arzobispo a D. GUTIERRE DE CARDENAS (ACT Z.6.A.2.2).

14 Definitivamente íntegra como propiedad del arzobispo en 1331, julio, 29 (ACT).

15 Ya constituida en villa, en 1466 se vendea Luis Carrillo: J. LóPEZ DE AYALA, Álvarez DE TOLEDo, Catálogo monumental de la provincia de Toledo. Toledo, 1959; J. GonzÁLEZ, Reinado y diplomas de Fernando III, 3 vol. Córdoba, 1983, 1986.

16 Confirmación de la donación de Uceda por Enrique IV (1454-1474) sobre la de Fernando III en 1252. El fuero se data hacia 1250 (ACT V.2.D.1.3).

17 Archivo Regional de Madrid (ARM). Torrelaguna, 4.5/1.5. Autorización de Juan I a Pedro Tenorio para dar el rango de villa a Torrelaguna.

18 En 1380 ya está integrada en el mayorazgo de Hita, fundado por Pedro González de Mendoza: J. Catalina Garcia, «Relaciones topográficas de España. Relaciones de pueblos que pertenecen hoy a la provincia de Guadalajara, con notas y aumentos", Memorial Histórico Español 41(1903) pág. 423. Transcrito.

ig J.A. García LuJÁn, op. cit., doc n. 103 ; J.F. Rivera Recio, Los Arzobispos de Toledo en la Baja Edad Media. Toledo, 1969.

20 Definitivamente y como fin a un conflicto con el Cabildo iniciado en 1159. J.A. GaRcía LUJÁN, Op. cit, doc n. ${ }^{\circ}$ 102. R. IzQuierdo Benito, El patrimonio del cabildo de la Catedral de Toledo en el siglo XIV. Toledo, 1980. págs. 168, 210, sitúa en 1357 una permuta del señorío de lllescas del Cabildo, en beneficio del arzobispo. ACT O.7.A.4.1, .2, .3, .4, y .6. El proceso discurre desde 1186-1187, marzo, 11, momento de la donación lllescas y Azaña por el Arzobispo Juan al Cabildo (ACT O.7.A.1.16). Sin embargo parece existir un traslado de 1322 de la donación realizada en 1159 (ACT O.7.A.1.3; y ACT O.7.C.1.4 (trasłado). J. GONZÁLEZ, El reino..., doc n. ${ }^{\circ} 263$; J.A. GARCÍA LUJÁN, Op. cit., doc n. ${ }^{\circ} 26 ;$ J. F. Rivera Recio, La lglesia... II págs. 75,82 y 86; F.J. HeRnÁNDEZ op. cit, doc n. ${ }^{\circ} 176$ y doc n. ${ }^{\circ} 177$. Es el rey Sancho IV y no el arzobispo quien da fuero a la población en 1291 (O.7.A.1.2b).

21 F. JIMÉNEZ DE GREGorio, "Tres puentes sobre el río Tajo en el Medievo", Hispania XIV (1954), págs. 163-226. 


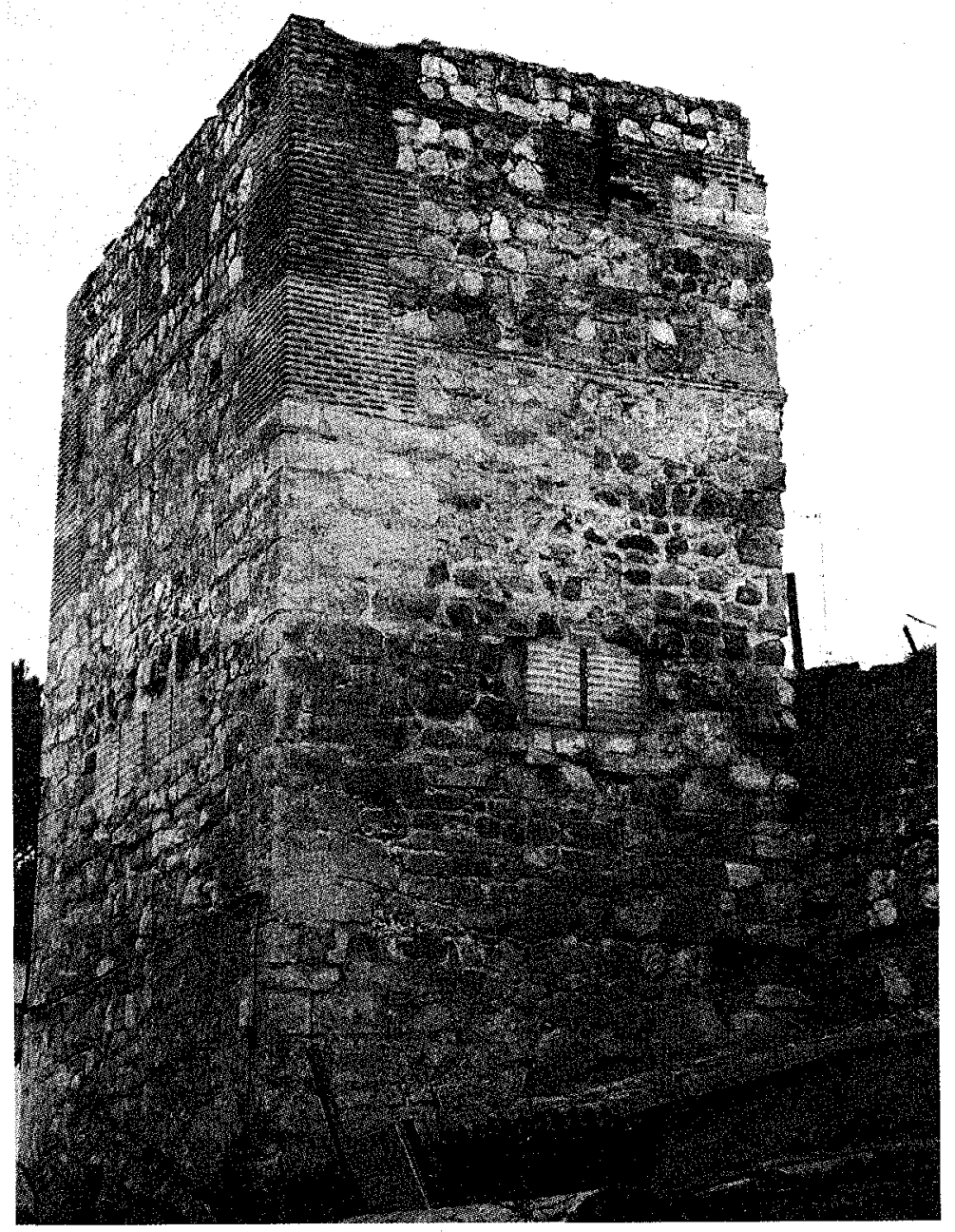

Fig. 2. Torre de la cerca de Talamanca. 
Alcolea, propiedad del arzobispo desde 1086. Al mismo Pedro Tenorio se debe la incorporación de las villas de Alcolea de Torote (hoy desaparecida) y Utrilla ${ }^{22}$. En esta segunda mitad del siglo XIV se tiene la primera constancia de la pertenencia de Santorcaz al arzobispo de Toledo, aunque se desconoce cuándo la villa se incorpora a la Mesa arzobispal ${ }^{23}$.

Esta nómina de villas, junto con aldeas y lugares, es la que se reitera en documentos del siglo $x V^{24}$. Se mantiene hasta 1574 , en que la Bula de Gregorio XIII faculta a Felipe II para la enajenación y venta de los bienes del arzobispo de Toledo ${ }^{25}$.

Este mapa de las villas de la mesa arzobispal responde a un estudiado control del territorio, que en primera instancia se apoya en el trazado de las vías de comunicación. Son fundamentalmente las que marcan los cauces fluviales de la Cuenca del Tajo, las conexiones de Toledo con Alcalá de Henares y Madrid, y la ruta hacia Andalucía, primero por el Puerto del Milagro, luego por el Muradal.

El primer periodo en la formación de las villas del arzobispo coincide con el control de la frontera con Al-Andalus. Se puede acotar entre $1086 \mathrm{y}$ 1212, con el hito intermedio de la conquista de Cuenca en 1177.

Progresivamente el control del territorio va alterando sus coordenadas, adaptándose al reparto de poder territorial en la Corona de Castilla, y a las

22 Según se recoge en el testamento: E. Narbona Historia de Don Pedro Tenorio, arzobispo de Toledo. Toledo, 1624.

23 E. Narbona op. cit.. Para Santorcaz vid. A. Echevaría ARSUAGa, «Los castillos de Alcalá la Vieja y Snatorcaz en la frontera cristiano musulmana española", Congreso de jóvenes historiadores y geógrafos. Madrid, 1990, págs. 631-642.

Sólo algunas otras villas de adscripción esporádica, tienen un vínculo con la Mesa Arzobispal de origen difuso. Tal es el caso de Perales (donde el arzobispo posee en el xv un importante castillo), o Villanueva de Bogas, al abrigo del castillo de Bogas (del arzobispo desde 1211 F.J. Hernández, Los Cartularios..., doc n. ${ }^{\circ} 323$ ). En cuanto a Huete, Valdemoro o Morata, son villas del arzobispo en el siglo xv (E. Benito Ruano, op. cit. págs.77-104). En diciembre de 1393, Enrique III, por Real Carta, da al arzobispo de Toledo Valdemoro y Morata (CANTO; EL turismo en la provincia de Madrid. Madrid, 1926). A fines del siglo xiv Valdemoro obtiene el rango de villa, pasa a los arzobispos de Toledo, según carta de Enrique III. Esta soberanía se le reconoce (con antigüedad de 150 años en Real Cédula de Carlos I en 1552) a Valdemoro,

${ }^{24}$ E. Benito Ruano, op cit. págs.77-104. Para 1471 y 1486 vid. las nómina de propiedades de la mesa arzobispal publicadas por C. SAez y A. CASTILlo. El fondo medieval del Archivo Municipal de Alcalá de Henares, Alcalá de Henares, 1995. AMAH, carpeta 7, documento. 24. 1471, ene, 18. Segovia; y doc. núm. 35. AMAH, carpeta 11, fol. 1 y 2v. 1486, feb, 26. Madrid.

25 BN Ms. 13061. f. 186-187. Villas y lugares del Arzobispo de Toledo de su jurisdicción temporal y vasallos suios. En esta relación aparecen numerosas aldeas que a lo largo del XVI han logrado el rengo de villa, pero esta fecha las sitúa fuera de los propósitos del presente estudio. El documento es una relación de las villas vendidas a partir de la bula de 1574. De la venta sólo quedan a salvo Talavera, Alcalá, Santorcaz y Puente del Arzobispo. Brihuega será recuperada poco después. 


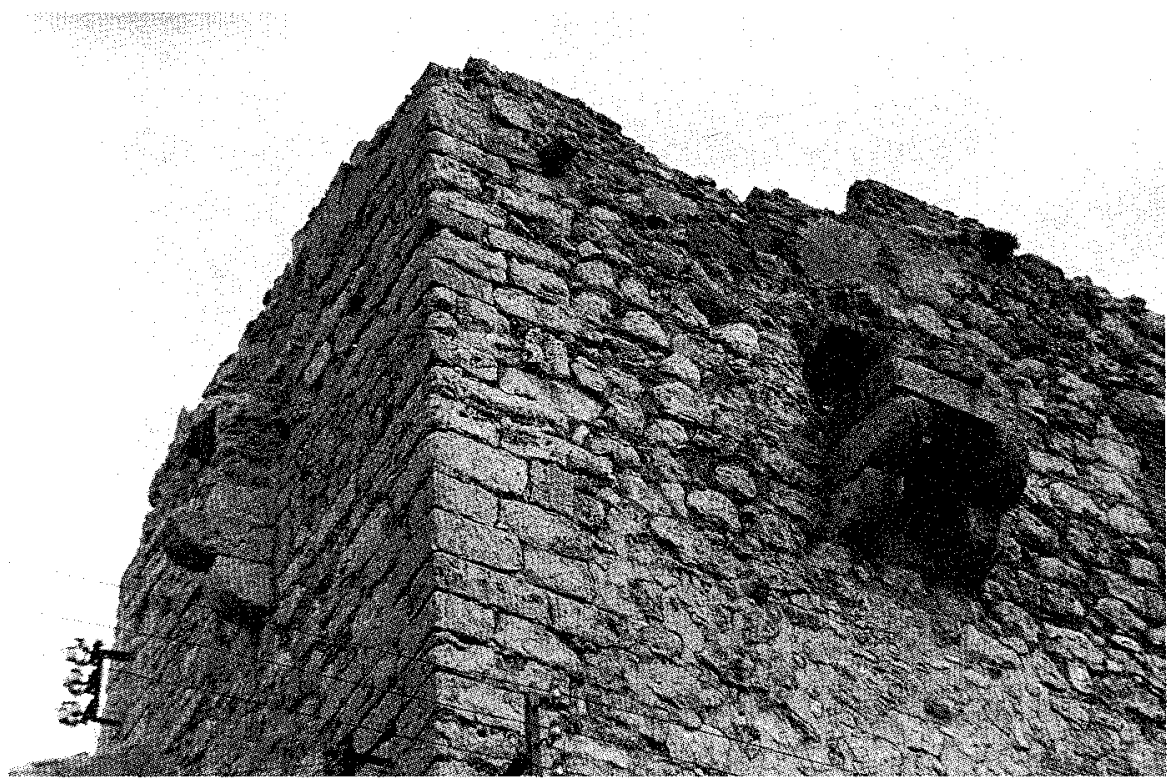

Fig. 3. Torre del primer recinto de Yepes.

fronteras con los reinos cristianos vecinos (Portugal, Aragón, Navarra). Este proceso es inmediato a la fecha de 1212, y se manifiesta especialmente a lo largo del siglo XIII. Responde a la política repobladora iniciada desde finales del siglo Xl, y que conoce su momento más destacado durante el XIII, principalmente con el arzobispo Rodrigo Jiménez de Rada. Esta actividad implica la promulgación de fueros y el establecimiento de mecanismos garantes de protección y defensa para las villas ${ }^{26}$.

El orden interno de Castilla en estas fechas supone el auge de las órdenes militares y de los concejos (poderes que habían irrumpido en el mapa a partir de la segunda mitad del siglo $\mathrm{XII}^{27}$ ); pero también la supremacía de la

26 J. García MARTín, «Fueros eclesiásticos de Toledo: ¿derecho territorial o derechos locales integrados en un régimen señorial?", Espacios y fueros en Castilla La Mancha (siglos XI-XV), una perspectiva metodológica. Madrid, 1995. págs. 203-254, ha insistido en la inicial situación de extremadura castellana de las villas del arzobispo de Toledo.

27 Para un estudio del papel y significado de la Iglesia Toledana y su relación con las Ordenes Militares D.W. LomaX, «El Arzobispo Rodrigo y la Orden de Santiago», Hispania, XIX (1959), y del mismo autor La Orden de Santiago (11701275). Madrid, 1965; E. RoDRíGUEZ-PICAVEA, La formación del feudalismo en la meseta meridional castellana. Los señorios de la Orden de Calatrava en los siglos XII-XII. Madrid, 1994. 
iglesia toledana sobre ellos. En este sentido, el apoyo de la monarquía al primado de Toledo es decisivo. Permite el afianzamiento del arzobispo en el territorio, donde sus villas son enclaves estratégicos. Belinchón, Yepes, La Guardia, Añover, Fuentes se sitúan cercanos a núcleos de la Orden de

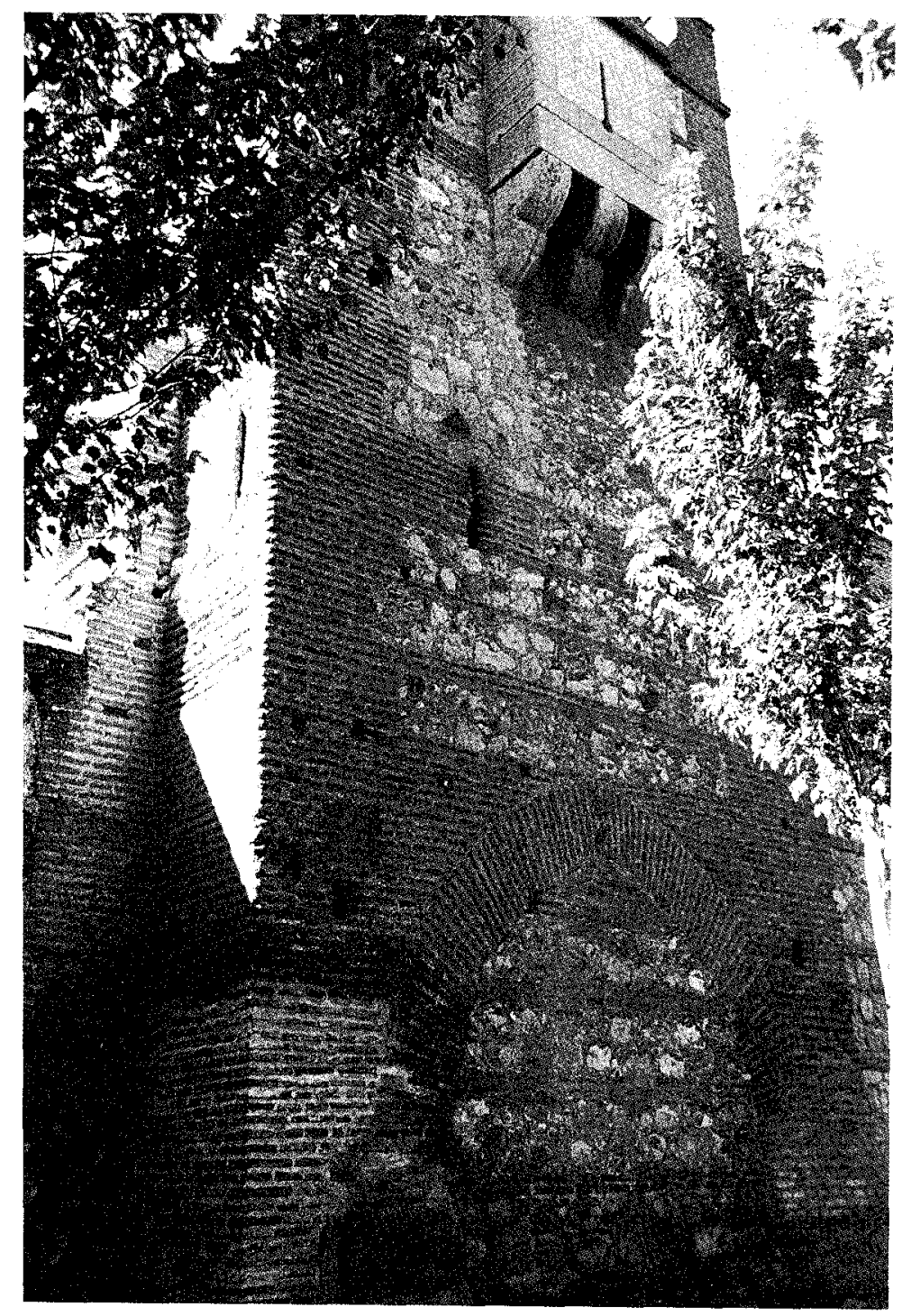

Fig. 4. Torre puerta de Alcalá de Henares. 
Santiago (Ocaña y Uclés) o de Calatrava (Ciruelos, Aceca, Zorita). Incluso villas como Brihuega, Fuentes, Utrilla o Huete (durante su esporádica pertenencia) tienen una posición privilegiada en el mapa de la archidiócesis, entre los Obispados de Sigüenza y Cuenca.

Este apoyo de la Corona posee un destacado componente económico y social (como el impulso a las ferias de Alcalá de Henares y Brihuega) que propicia el desarrollo de las villas, y las acometidas de embellecimiento y ampliación. La estabilidad iniciada en 1177 (conquista de Cuenca) contribuye a esta prosperidad urbana.

Por otra parte, Castilla conoce desde los últimos años del siglo XIII una inestabilidad política que se traduce en enfrentamientos internos. Este marco concede al arzobispo y a sus villas un papel relevante en el desarrollo de los acontecimientos: conflictos dinásticos, como el enfrentamiento entre Alfonso $X$ y su hijo Sancho (fines del siglo XIII), las minorías de principios del XIV, el advenimiento de los Trastámara (último tercio del XIV) y la guerra civil que ocupa el siglo xv, hasta la llegada al trono de Isabel la Católica.

Un último punto de interés es el de la posición de la Corona castellana en el mapa peninsular cristiano. Las villas del arzobispo en las fronteras de Portugal y de Aragón tienen más de una ocasión para comprobar el valor de su posición estratégica.

La línea Alcalá de Henares - Brihuega hacia la frontera con el Reino de Aragón, tiene su máximo valor de avanzadilla en el siglo xill (momento en que la Iglesia de Toledo se expande a costa de la Orden de Calatrava) y en los años centrales del xV. Pedro Tenorio posee un papel destacado en la consolidación de esta zona (al incorporar Utrilla y Almaluez) en la segunda mitad del siglo XIV; el mismo momento en que los conflictos con Portugal explican que dicho arzobispo controle las posiciones de Talavera y la Villafranca de la Puente del Arzobispo.

Este trasfondo histórico permite atordar la evolución tipológica de las villas del arzobispo entre los siglos XI y XV, y en primera instancia la arquitectura militar y de delimitación espacial ${ }^{28}$, como elemento característico de la ciudad medieval.

Pueden establecerse a priori dos fases. A un primer momento, que transcurre hasta mediados del siglo XIV, corresponde la configuración espacial de las villas del arzobispo.

\footnotetext{
28 Queda al margen de este estudio la organización social del espacio y la organización del viario, apartados del análisis tipológico urbano ya establecidos en estudios anteriores. Vid. M. ${ }^{a}$ M. Merlos Romero, op. cit.
} 
Los fueros de fines del XII y principios del XIII pautan el plan director del desarrollo urbano de las villas, caracterizadas por la presencia de tres constantes, iglesia, fortaleza y muralla urbana.

Sin embargo, estas villas están determinadas por la herencia del sistema de administración espacial islámico. Tienen su origen en un lugar fortificado de mayor o menor envergadura, en ocasiones un castillo, obra islámica o preislámica, que el arzobispo se reserva para sí (Brihuega, Alcalá la Vieja, Yepes). Esta misma herencia explica que la iglesia ocupe el solar de la mezquita o la transforme, ilustrando la restitución del credo cristiano (Talamanca). Sólo la cerca urbana responde a una creación cristiana ${ }^{29}$.

Un segundo momento (segunda mitad del siglo xIV y siglo $\mathrm{xV}$ ) se caracteriza por la formación de nuevas villas, e incluso la transformación de las ya existentes.

Algunas villas surgen por la recuperación de un núcleo despoblado o de un castillo abandonado (Villanueva de Bogas junto a Bogas, Villafranca del Arzobispo en el territorio de Alcolea). Más frecuente es que una aldea alcance el rango superior de villa, como sucede en el Adelantamiento de Cazorla, donde una mayor estabilidad permite la consolidación urbana (Villanueva del Arzobispo, La Iruela). Esto sucede también en el entorno del Tajo (Torrelaguna, Torrijos, Lillo, El Romeral).

Estas dos fases en la formación de las villas se reflejan en la evolución formal y conceptual del castillo (o fortificación) y de la cerca urbana, así como en las relaciones entre ambas.

Los castillos que entre los siglos XI y XIII recibe el arzobispo mantienen, en un primer momento, la función de control del territorio y defensa que poseían durante el dominio islámico.

El arzobispo recibe castillos de situación crucial, desde la propia dote fundacional de 1086 (Almonacid, Alcolea, Brihuega), a los que se suman, a partir del hito histórico de la conquista de Aurelia en 1139, otros como Bolobras $\left(1142{ }^{30}\right)$, Canales $\left(1143^{31}\right)$, Belinchón, Calatrava, San Servando (1175).

29 Salvo en aquellos casos en que el arzobispo hereda un núcleo de especial relevancia, una ciudad, como puede ser Talamanca.

${ }_{30}$ Recibido en 1142 (ACT A. 10.K.1.1 y 1a; F.J. HeRNÁNDEZ, Los cartularios..., doc. n. ${ }^{\circ} 84$ ). En 1152 es donado por el arzobispo a Hugo, canónigo toledano cluniacense (F.J. HERNÁNDEz, Los cartularios..., doc. $n{ }^{\circ} 85$ ).

31 ACT A. 11. K. 1. 1; F.J. Hernändez, Los cartularios..., doc. n. ${ }^{\circ}$ 47; R. IzQuierdo Benito, op. cit., pág. 68; J. F. Rivera Recio, La Iglesia... II, pág. 70. 
Significativa debe ser la cantidad y calidad de los castillos de la Iglesia, y su distribución en el mapa, cuando en 1204, Alfonso VIII hace público que todos los castillos episcopales del reino lo son, en última instancia, de su hijo y sucesores, por cuanto su fin es el de servir a la Corona de Castilla ${ }^{32}$.

Pero no todos estos castillos conocen idéntica evolución. El arzobispo ya se había desentendido de algunos durante la segunda mitad del siglo XII (Bolobras, Ribas, Calatrava). El proceso de transferencias es especialmente significativo con $\mathrm{D}$. Rodrigo Jiménez de Rada, quien se desprende de Pulgar y los castillos del entorno del Puerto del Milagro ${ }^{33}$. Estos enclaves han perdido su valor estratégico respecto de la frontera con AlAndalus, pero también respecto de la conformación interna del reino de Castilla. Otros castillos se mantienen como tales, con una exclusiva función militar (Alcalá la Vieja, Almonacid) o decaen (Alamín, Alcolea) hasta el despoblado y el abandono.

Otro nutrido grupo, entre la segunda mitad del XII y principios del XIII, mantiene su valor estratégico y es el origen de las villas más antiguas del arzobispo (Belinchón, Brihuega, Alcalá) ${ }^{34}$.

El núcleo defensivo heredado puede ser de cierta entidad (Alcalá) o en ocasiones una alquería, con un recinto de mayor o menor envergadura (Yepes ${ }^{35}$, Brihuega ${ }^{36}$ ). En cualquier caso, es significativo que dicho núcleo se identifique con el arzobispo, como señor de la villa. En ocasiones el primado recibe esta propiedad islámica a través de una fase de propiedad real, lo que enfatiza el valor de la arquitectura recibida y su significado (Brihuega, y tardíamente en el XIV Talavera).

32 J. GONZÁLEZ, La repoblación..., pág. 199.

33 Ribas (ACT O.11.A.1.21; F.J. HeRnández, Los Cartularios..., doc n. ${ }^{\circ} 94$ ) lo dona en 1154 a Pedro Cruzado para que lo gobierne y pueda levantar una cerca en el castillo(ACT X.11.F.1.2, J. González, La repoblación... l, págs. 109, 125; F.J. Hernández, Los Cartularios..., doc. n. ${ }^{\circ} 117$; J.A. García Luján, Op. cit., doc. n. ${ }^{\circ}$ 20).

En 1214 Milagro pasa a la Iglesia de Toledo (J. GonzÁlez, El reino..., doc. n. ${ }^{\circ} 965$; J. GonZÁlez, La repoblación..., pág. 287 n. ${ }^{\circ}$ 421. En 1222 se dona a la Catedral de Toledo la villa de Pulgar (J. González, El reino..., doc n. ${ }^{\circ}$ 966. J. González, Reinado..., doc. n. ${ }^{\circ}$ 155.) En 1221 permuta de los castillos de Santa Cruz, Mira y Serrelam para recibir a cambio Mora y Vallacroch (1221, noviembre 30. ACT E.12.0.1.3)

Fernando III concede en 1222 los castillos situados en término de Navahermosa: Dos Hermanas, Cedenilla, Malamoneda y Muro (J. GonZÁLEZ, Reinado..., doc. n. ${ }^{\circ} 153$; J.A. GARCÍA LuJÁN, Op. cit, doc. n. ${ }^{\circ}$ 57; F.J. HeRNÁNDEZ, Los Cartularios..., doc n. 403 . Se desprende en 1243.

${ }^{34}$ Este proceso será idéntico, pero más tardío para los castillos del Adelantamiento de Cazorla, incorporados durante el segundo tercio del siglo xill, momento en el que predomina su función militar.

35 M. Merlos Romero, op. cit.; F.J. Hernández, Los Cartularios..., doc n. ${ }^{\circ} 360$.

${ }^{36}$ M. Merlos Romero, "El castillo de Brihuega y sus origenes islámicos", Espacio, Tiempo y Forma, Serie VII, Historia del Arte,12 (1999), págs. 41-60. 


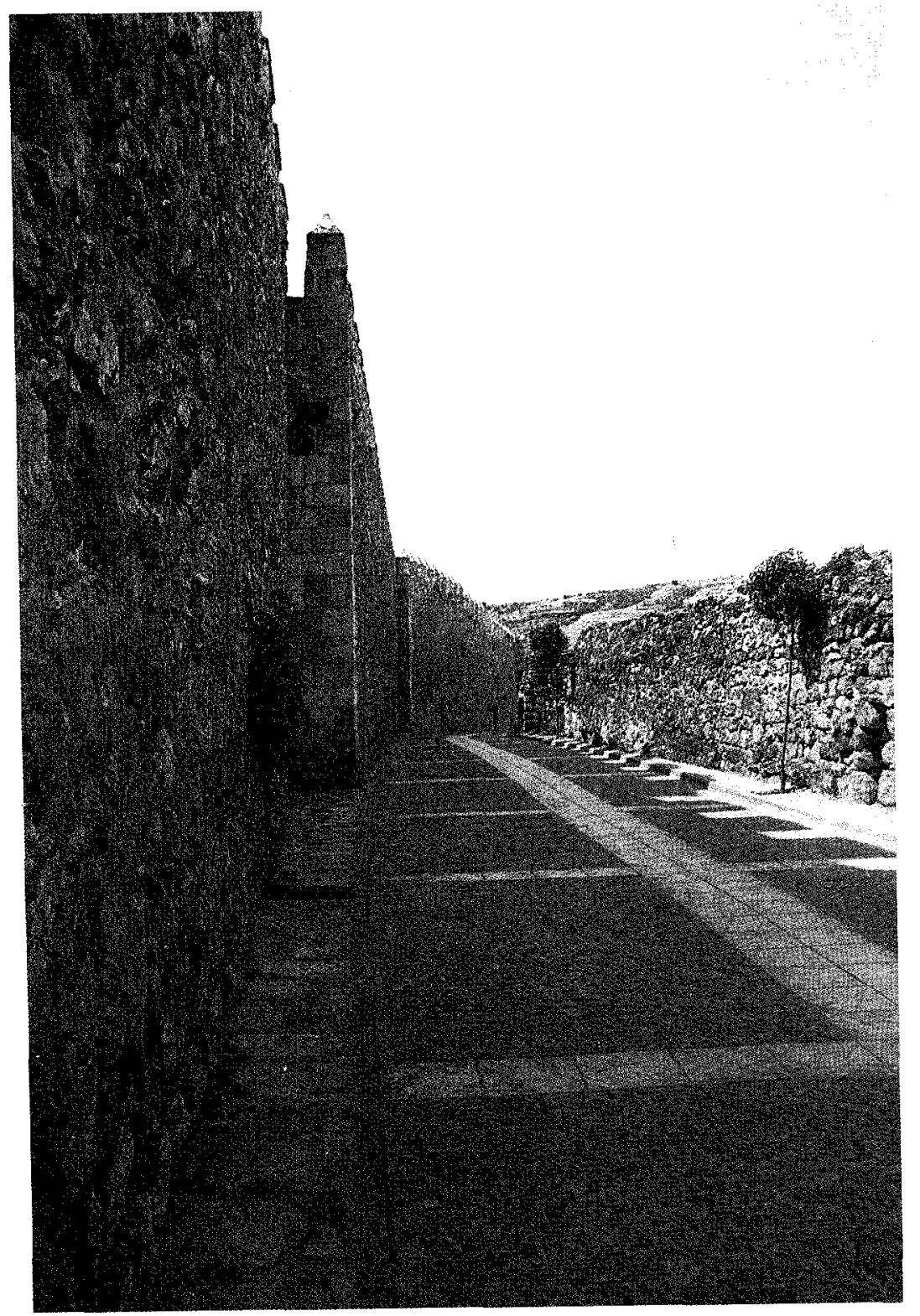

Fig. 5. Zigzag flanqueante de la cerca de Brihuega. 
El arzobispo toma una arquitectura militar heredada, a la que aúna una función institucional e incluso, en ocasiones, residencial. Este modelo funcional es el que el arzobispo llega a reproducir en construcciones de nueva planta, como el alcázar de Illescas ${ }^{37}$ o el Palacio de Alcalá de Henares.

Sin embargo el modelo no perdura hasta el fin de la Edad Media. Durante el siglo xv las obras de nueva planta estarán más próximas a la tipología de casa fuerte (palacios de Yepes y Talamanca, nuevas construcciones de La Guardia), determinada por la adaptación a la vida urbana.

Tanto el valor defensivo como institucional del castillo explica las iniciativas de los reyes castellanos por arrebatar los castillos al arzobispo, o lo que es lo mismo, de apropiarse de su señorío, en momentos de conflictos de poder entre la corona y la mitra. Al arzobispo Tenorio le retienen varios castillos (Uceda, Talavera, Alcalá la Vieja, La Guardia... ${ }^{38}$ ), que sólo le serán restituidos por decisión papal en 1393. Los procesos de reconstrucción del sistema militar de la mitra toledana, como el de Pedro Tenorio a fines del XIV ${ }^{39}$, confirman la vigencia - y necesidad - de la función defensiva.

La toma de los castillos del arzobispo por parte de los Reyes Católicos será el primer golpe mortal al señorío del arzobispo, cuya mapa se mantendrá más o menos íntegro hasta la época de Felipe II, pero ya desprovisto de una función militar al servicio del primado. Cuando en 1479 los Reyes Católicos perdonan la actitud del arzobispo (que había tomado partido por Juana la Beltraneja), le exigen a cambio la entrega de sus fortalezas de Alcalá la Vieja, é Brihuega, é Santorcaz, é La Guardia, é Almonacil, é Canales, é Uceda, en las quales el Rey é la Reyna pusieron sus alcaudes, que les ficieron pleyto omenage, é prometieron de no acoger en ellas al arzobispo, ni a otra persona alguna sin su mandato ${ }^{40}$. Con esta medida, no sólo se está neutralizando el poder militar del arzobispo, sino que se está dando fin a un señorío en su concepto medieval.

A diferencia del castillo, la muralla urbana no es una arquitectura heredada por el arzobispo, sino una creación generalmente simultánea a la formación de la villa ${ }^{41}$. Por ello no sólo posee una función defensiva, sino también delimitadora del espacio urbano respecto del resto del territorio.

37 De hecho el alcázar de Illescas promovido por Juan de Aragón es derribado por Alfonso XI en 1323, pues representa el poder del arzobispo en una villa, con un conflicto jurisdiccional que no se salda a favor del arzobispo hasta 1369. Archivo Municipal de Illescas (AMI), CP 2/2.

38 1393, jul, Burgos. ACT E.12.0.1.8

39 E. NARBONA, op cit.

40 P. López de Ayala, Crónica de los Reyes de Castilla. Madrid, 1953. Vol. III, pág. 338.

41 Excepción es Talamanca, ciudad bajo el dominio islámico, o Talavera, de idéntico origen a Talamanca y, además, transformada por la corona castellana antes de su tardía incorporación al señorio del arzobispo. 
De alguna manera, la existencia de la cerca se deduce del hecho de promulgación del Fuero. Su construcción puede vincularse a la constitución de las villas. De tal modo que la cronología de los fueros contribuyen a la datación del fenómeno del amurallamiento, al menos a confirmar la existencia de la cerca en el momento de concesión de fuero. De hecho algunas de estas cercas se están levantando a finales del siglo XII, como sucede en Brihuega, aunque sus fueros se datan entre 1223-1240. De 1259 es una noticia donde se constata la función de la cerca como elemento delimitador del espacio urbano ${ }^{42}$.

La política repobladora del arzobispo Jiménez de Rada concede los fueros citados de Brihuega, así como los de Yepes ${ }^{43}$, La Guardia, Alcalá de Henares (texto refundido); confirmándose documentalmente la existencia de cerca urbana en dichas villas a mediados del siglo XIII. La pareja expansión económica hace presuponer, en igual medida, la existencia en las villas de un imprensindible recinto amurallado que permita la organización

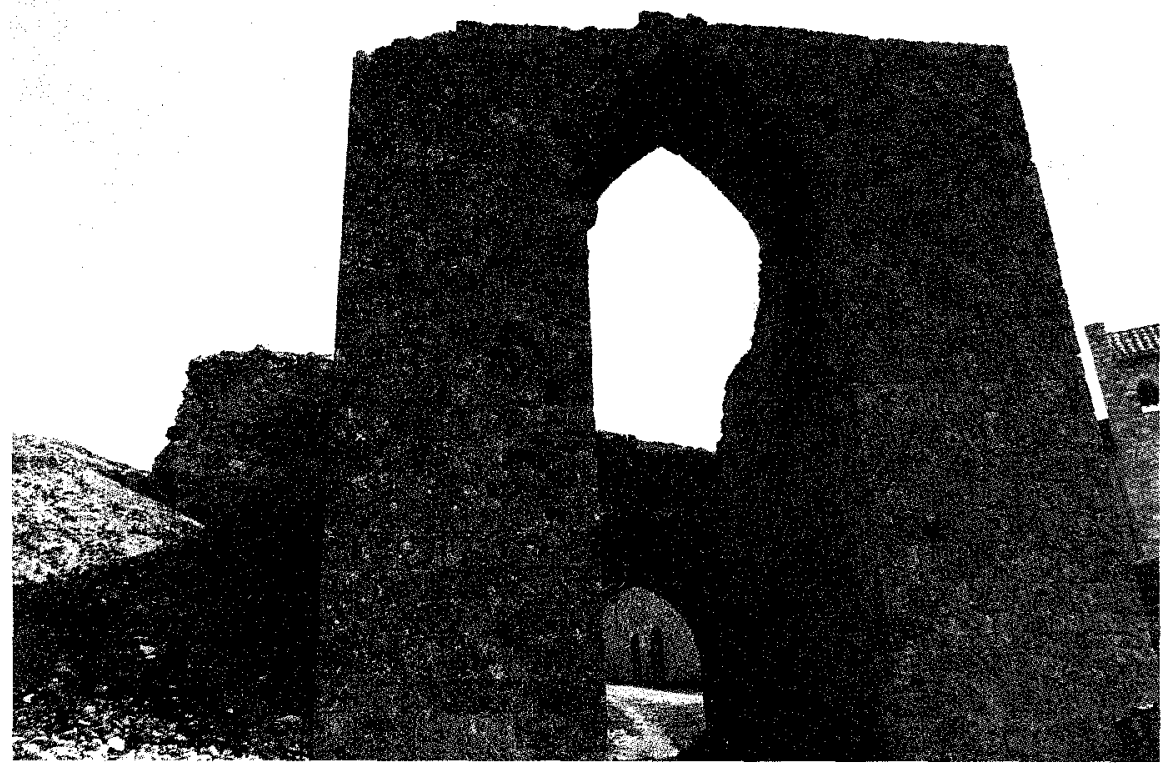

Fig. 6. Puerta de Cozagón (Brihuega).

42 Domingo Perez su repostero mayor que non salca de Briuega de los adarves a fuera por sos pies...el saliese de Briuega de los adarves.. A. PAREJA SerRadA, Diplomática Arriacense, Guadalajara, 1921, pág. 347.

43 F.J. HERNÁNDEZ, Los Cartularios..., doc. n. ${ }^{\circ} 360$. 
de ferias y el cobro de los impuestos establecidos foralmente. Precisamente las ferias más antiguas otorgadas por los reyes castellanos son las dadas a instancia de los arzobispos de Toledo ${ }^{44}$. Los reyes persiguen el apoyo político de la Iglesia, anhelo que propicia la institución de las ferias de Brihuega o de Alcalá de Henares.

Un nuevo hito en la creación de murallas (Fuentes ${ }^{45}$ y tal vez Santorcaz) y remodelación de las existentes (Brihuega) se produce en el paso del siglo XIII al XIV. Viene determinado por la pugna por el poder entre Alfonso X y Sancho IV y por la incertidumbre y la inestabilidad políticas durante las minorías reales castellanas ${ }^{46}$ (reinados de Fernando IV y Alfonso XI); pero también por el desarrollo económico, derivado de los beneficios arrancados por el arzobispo al rey ${ }^{47}$.

Un nuevo momento de actividad edificatoria se produce en el último cuarto del siglo XIV, favorecida por una recuperación de las recién pasadas epidemias de peste y guerras civiles. El programa de reconstrucción de arquitectura militar (en castillos como Canales, Alcalá la Vieja, Santorcaz, Almonacid y en el recinto menor de Yepes) promovido por el Arzobispo Pedro Tenorio ${ }^{48}$, alcanza también a cercas urbanas (Brihuega ${ }^{49}$, Alcalá de Henares, Torrelaguna, Talamanca del Jarama, Uceda).

Un último hito a destacar es la posición política del arzobispo Carrillo Acuña en el contexto de la sucesión al trono de Juan II, y en los primeros años de mandato de los Reyes Católicos. La situación ilustra la vigencia

44 M. Ladero Quesada, «Las ferias de Castilla. Siglos XII a XV», CHE, LXVII-LXVIII (1982), pág. 289.

45 La muralla y castillo de Fuentes son levantados por Gonzalo Pétrez (P. MARTínez TABOADA, Urbanismo medieval y renacentista en la provincia de Guadalajara: Sigüenza, un ejemplo singular, 2 vols. UCM, Madrid, 1990, pág. 407, 413; F. LAYNA SERRAno, Castillos de Guadalajara. Guadalajara, 1994. pág. 48).

46 En este contexto también ha de entenderse la solicitud que realiza el arzobispo Gonzalo Pétrez de un préstamo para mantener abastecidos los castillos de la frontera. ACT A.7.G.1.18. Cfr. R. GonzÁlvez, Hombres y libros de Toledo, Madrid, 1997. pág. 394.

47 Los derechos de portazgo de Brihuega y de otras tres importantes villas del arzobispo en 1301 en el eje Toledo-Zaragoza (Alcalá, Uceda y Talamanca; ACT O.2.Q.9.5) ilustran el peso de estas ganancias en el patrimonio del arzobispo, percibidas a través de un verdadero sistema recaudatorio, cuya base es el poder territorial de su señorío.

48 F. Layna Serrano, op. cit, pág. 47; pág. Narbona, op cit; A. Turina, «El Castillo de Alcalá de Henares", Madrid del siglo ix al Xl. Madrid, 1990, págs. 189-194. B. PAvón Maldonado, Alcalá de Henares, islámica y mudéjar. Madrid - Alcalá de Henares, 1982. En el caso de Uceda se confirma la fecha de 1386, en la que los vecinos de Torrelaguna están eximidos de contribuir a la reparación de las defensas de Uceda (Archivo Regional de Madrid (ARM) Torrelaguna, 4.5/1.4.

49 Cercana a Molina, que seguirá siendo un bastión favorable a la causa de Pedro I, aun terminada la guerra civil. 
de las necesidades defensivas en las villas del arzobispo. A este momento tal vez correspondan intervenciones en las cercas de Alcalá de Henares (ampliación), Yepes (el recinto mayor), Talavera (tercer recinto), Uceda.

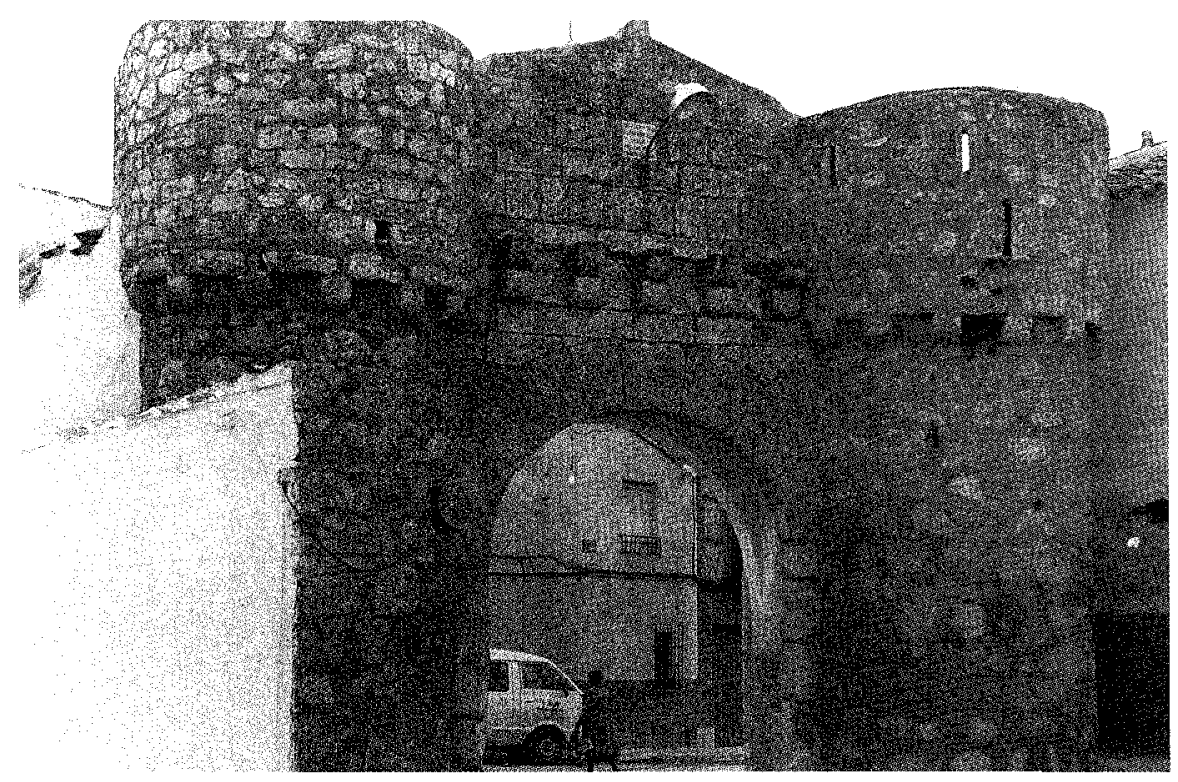

Fig. 7. Puerta del recinto mayor de Yepes.

Queda claro que las funciones defensivas de las cercas se perpetúan hasta el $x V$, en el panorama de las contiendas castellanas bajomedievales. Pero no es menos cierto que el concepto cristiano de ciudad confiere a la muralla urbana nuevos valores, como delimitadora del espacio urbano (la contraposición ciudad/campo), o como identificadora de la urbe, entendida ésta como ámbito sociopolítico, y de desarrollo comercial y económico. Ello permite destacar las relaciones entre la cerca y la organización de ferias, mercados, o cobros de impuestos (portazgo) ${ }^{50}$. Son estas funciones las que explican los procesos de reconstrucción y mantenimiento de murallas urbanas hasta entrado el siglo $\mathrm{XV}{ }^{51}$.

50 Resulta por la tanto obvio que una villa de nueva creación como la Villafranca del Arzobispo, al concebirse como un paso franco sobre el Tajo, no sea dotada de cerca urbana.

51 Reconstrucción de la cerca de Yepes en 1500 con cimientos de piedra, alzado de tapial y un remate de almenas en yeso (Archivo Municipal de Yepes (AMY) C.a 1/1. Fol. 10). En Illescas, en 1499 reparaciones de portillos de pilas e cava y dos almenas (AM], L. 1 de Actas Municipales, fol $L X X I I)$, y referencias a pleito con la villa de Madrid por el reparo de las puertas de la cerca (AMI, L 1 de Actas Municipales, fol. CXXVIII) 


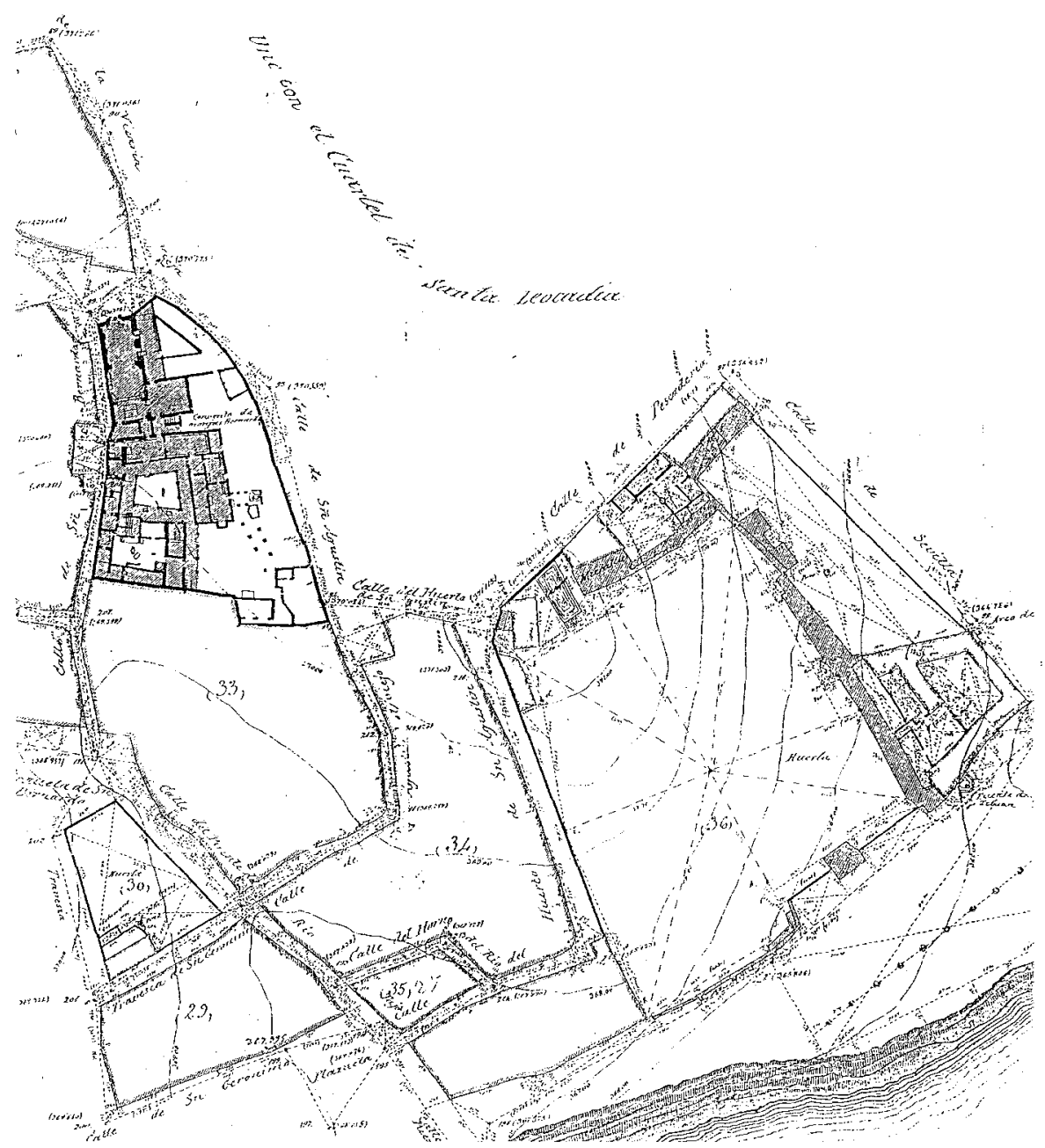

Fig. 8. IGN (Instituto Geográfico Nacional). S. xIx. Plano de Talavera. Detalle del alcázar y del primer recinto. 
La pluralidad funcional de la cerca urbana permite comprender asimismo, algunos de los aspectos y peculiaridades de su evolución tipológica durante la Edad Media ${ }^{52}$. La pervivencia de los modelos islámicos no se produce de una manera homogénea. Así, los materiales y técnicas constructivas empleados apenas se modifican, debido desde luego más bien a una tradición arraigada, que a una pervivencia. Así sucede con el tapial, muy difundido en las torres y muros en las cercas más antiguas (Alcalá de Henares), y de empleo casi exclusivo para muros en cercas más tardías (fines del XIV, XV, Lillo, segundo recinto de Yepes, sobre una base de mampostería, o tercer recinto de Talavera) ${ }^{53}$.

La evolución funcional determina distintas fases en la formación de las cercas. Las más antiguas se caracterizan por la abundancia de torres que las jalonan (Alcalá de Henares, ángulo común con el palacio principalmente, primer recinto de Yepes, Villeta de la Guardia); y la incorporación entre éstas de tipologías de mayor potencial poliorcético, como las albarranas de tradición islámica (Santorcaz, Alcalá de Henares, Talavera ${ }^{54}$ ), o las torres pentagonales (Santorcaz), presentes tanto en el Islam (Calatrava la Vieja) como en el mundo cristiano.

Un punto intermedio en esta evolución lo constituye la suplantación de torres mediante el sistema de zigzag flanqueante (Brihuega y Almonacid). La fase final del proceso se identifica con cercas sin torre, como se detecta en el paso del siglo XIV al XV en ampliaciones de recintos (Yepes, Santorcaz, tercer recinto de Talavera) y en las cercas de las nuevas villas (Lillo, Torrelaguna, Torrijos). En estas cercas, realizadas exclusivamente en tapial, los muros presentan una escasa elevación respecto de las murallas urbanas anteriores.

En las cercas más recientes los recursos se concentran en las puertas, utilizadas para dignificar la imagen urbana, y marcar el ingreso a un recinto acotado y diferenciado, que anuncia la ciudad (Torrelaguna, segundo recinto de Yepes). En las puertas es donde se subraya el concepto político y administrativo de la villa sobre la originaria función defensiva de la muralla urbana. Por ello, el modelo más frecuente es el de paso directo entre dos torres. Sin embargo, su monumentalidad es casi

52 No se abordan ahora valoraciones formales de estos elementos, objeto de otro trabajo.

53 El empleo del sillarejo puede aparecer aparece en lienzos de las cercas más antiguas (Brihuega) y se limita en las intervenciones del xv a puertas (Brihuega, Yepes). Estos materiales conviven con el ladrillo, presente con frecuencia en torres (Yepes, Alcalá) y puertas (Torrelaguna, Talamanca).

54 Está por precisar si en el caso de Talavera la incorporación de albarranas al primer recinto es obra de los arzobispos de Toledo o de la Corona, la propietaria de la ciudad hasta 1369. 
excepcional (y localizada en cercas del XIII y xIV: Puerta de Cozagón en Brihuega, o Puerta de Uceda en Talamanca). Más bien responden a una escala modesta, en cualquier caso proporcionada respecto de la escasa elevación de estas cercas más modernas. Las puertas con una manifiesta función defensiva corresponden a momentos anteriores, aunque pueden alcanzar incluso el último cuarto del siglo xIV. Sirvan de muestra las puertas acodadas (Santorcaz y posiblemente primer recinto de Yepes), o las torres puerta (Alcalá de Henares y Puerta de Malacuera de Torrelaguna).

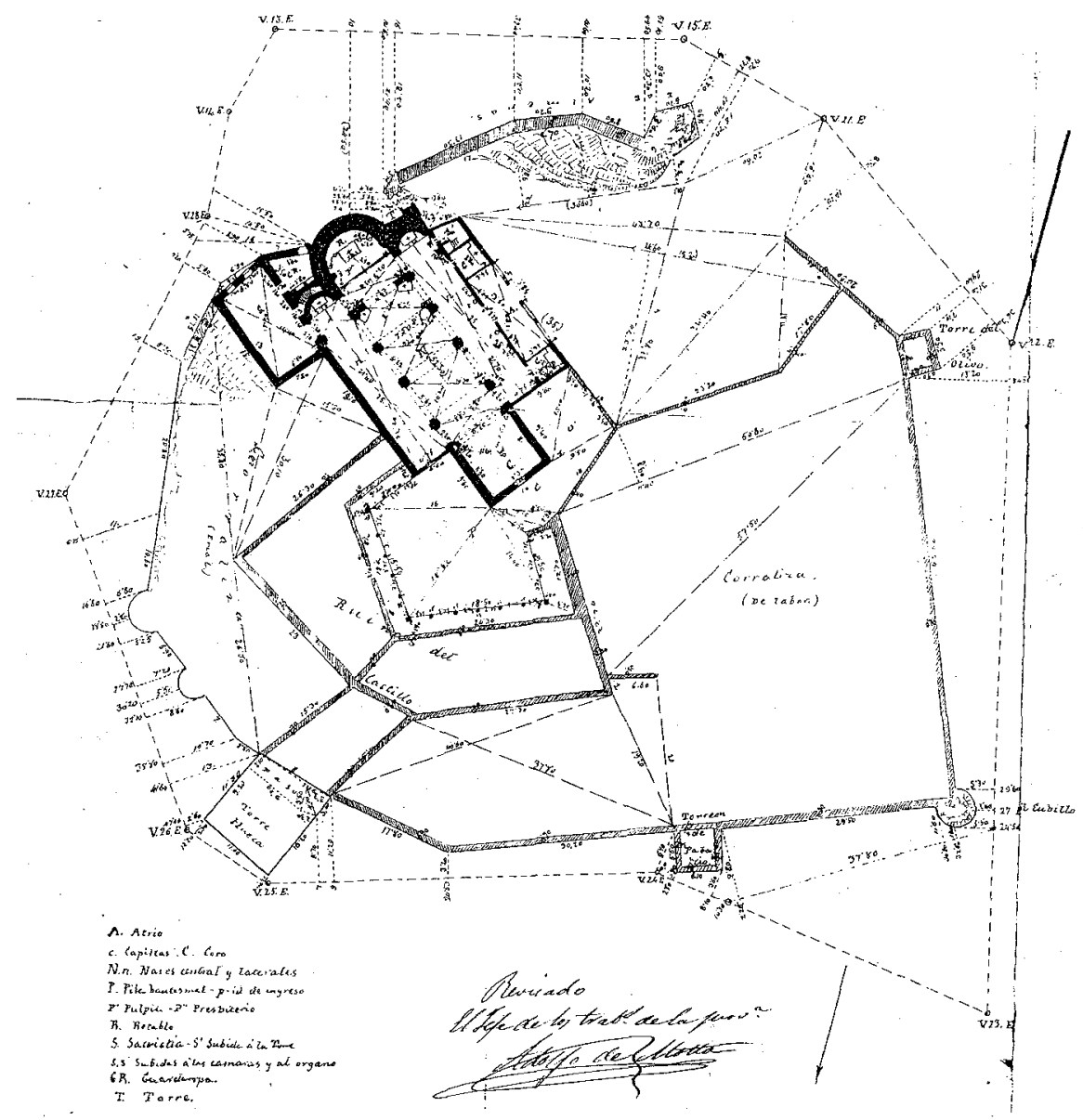

Fig. 9. IGN. S. XIX. Plano de Santorcaz. 
Un último aspecto de interés es el de las relaciones establecidas en la villa, sobre la base de la organización del espacio, entre el núcleo defensivo (castillo) y la cerca urbana.

Desde un punto de vista espacial, se asiste a un doble fenómeno. En algunas ocasiones, la villa se forma separada del castillo heredado (Alcalá de Henares, Almonacid), con una significativa bajada al llano de la población ${ }^{55}$. En otras ocasiones, el núcleo del castillo queda anexo a la villa amurallada, pero separado de la misma. Esta distinción física determina las relaciones orgánicas. En el primer caso el castillo se mantiene con una exclusiva función militar.

En el segundo supuesto el núcleo militar domina el conjunto urbano, en una cota más elevada, aunque hay excepciones (Yepes, Brihuega, La Guardia ${ }^{56}$ ). El castillo constituye uno de los cierres laterales de la cerca, pero manteniendo sus estructuras muy delimitadas. Esta desconexión entre castillo y cerca se manifiesta en el viario urbano. El núcleo militar queda separado de la villa por una línea de muralla, y su acceso limitado a un portillo o puerta única (La Guardia, Uceda, Brihuega, Yepes). A su vez, el castillo mantendrá una conexión independiente con el exterior, sin cruzar por la villa (primer recinto de Yepes, Alcalá de Henares, Illescas).

Este modelo ya era conocido en la ciudad islámica. Estos pequeños recintos respecto de la cerca urbana se convierten incluso en ciudadelas, que se identifican con el poder del señor, del arzobispo (La Villeta de La Guardia, Santorcaz, Yepes, Brihuega, Fuentes, Illescas, Uceda). Se establece así una relación de carácter sociopolítico entre castillo y cerca urbana. A la función defensiva se aúna una dimensión política y administrativa, ya que el castillo en un instrumento de control del señorío territorial del arzobispo. De tal modo que puede llegar a convertirse en sede del pallatium, como sucede en Brihuega ${ }^{57} 0$ en Alcalá de Henares, entendiéndose este concepto de palacio como institución testimonio del poder del arzobispo.

55 P. Lavedan, Histoire de l"Urbanisme Antiquité-Moyen Age, París, 1926, pág. 449-450, 453 define el modelo medieval de villa de accesión, caracterizado por la presencia de un castillo dominando la villa.

56 Las tres villas se desarrollan sobre una meseta, desde donde se asoman al valle por el Sur, como vestigio urbano de su primitiva configuración de control respecto del territorio: la ladera y el valle, por donde en época islámica debía dispersarse la población.

${ }_{57}$ Según el fuero de Brihuega, el palacio es la institución integrada por nos (el arzobispo) et nostras parsonas et nostros canonigos et nostros clerigos: mientre moraren en briuega. Vid. J. García Martín, op. cit. págs. 203-254. 


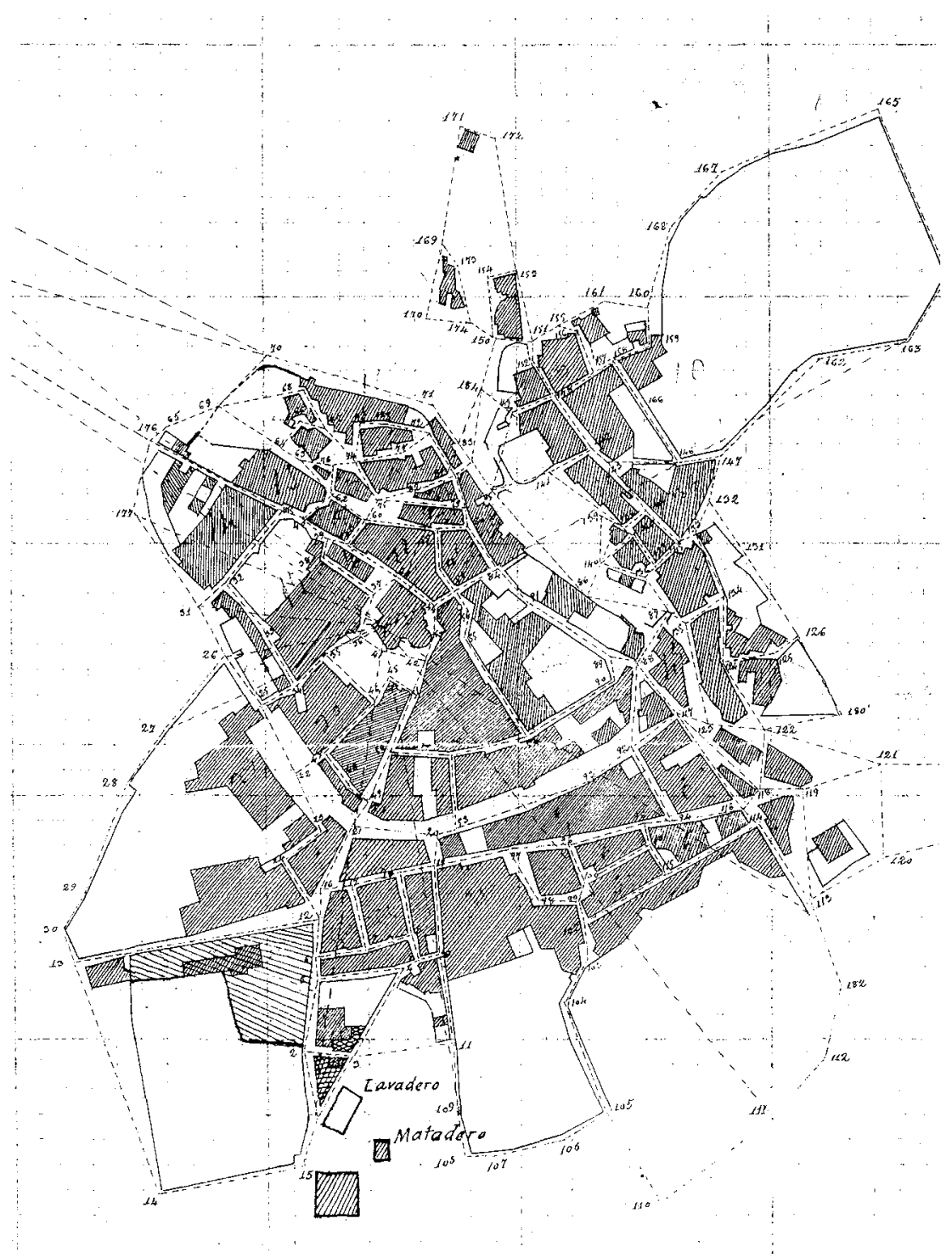

Fig. 10. IGN. S. XIX. Plano de Torrelaguna. 
Por otra parte, estas relaciones cerca-castillo explican que el protagonismo de la plaza como elemento urbano sea muy tardío. En los ejemplos citados no existe plaza, y de existir, no cuenta con la presencia de una arquitectura tan representativa como el templo (Brihuega, recinto mayor de Santorcaz). Generalmente el templo está incorporado en el recinto defensivo del arzobispo (Brihuega, Santorcaz, La Guardia ${ }^{58}$ ).

La plaza surge con una función comercial, y extramuros (Brihuega, Plaza Mayor de Alcalá de Henares, La Guardia) y sólo se incorpora a la villa en fases posteriores de expansión urbana. Es a partir de fines del siglo XIV cuando la plaza adquiere importancia, como centro aglutinante de la villa, de creación cristiana, como espacio público de primer orden. El esquema más frecuente incluye la iglesia y el lugar de reunión del concejo (lllescas) ${ }^{59}$.

Sin embargo, las nuevas villas del arzobispo, que se forman a partir de los años finales del siglo XIV, se organizan en torno a la plaza. En ella confluyen la iglesia y el palacio o casa del arzobispo, que orgánicamente viene a sustituir al castillo, adaptándose a una dimensión más urbana (Puente del Arzobispo, Torrelaguna). Ello explica que en las villas de nueva creación (Lillo, Torrelaguna) la cerca se conciba como un perímetro de delimitación, desprovisto de elementos defensivos tan significativos como las torres.

Excepcionalmente, algunas villas que conocen una expansión urbana a partir de fines del XIV y XV, compartirán este esquema, que se superpone a la trama anterior. Tal es el caso de la plaza de Yepes, donde el palacio ocupará el centro del espacio abarcado por la nueva muralla. Este modelo, por otra parte, es representativo de las villas de las órdenes militares (Almagro), donde la plaza aúna los edificios que simbolizan los poderes terrenal y espiritual.

En definitiva, parece que la expansión urbana que se inicia en la segunda mitad del XII en las villas del arzobispo implica la confluencia entre las primitivas funciones defensivas y los rasgos urbanos procedentes de un nuevo concepto, el de burgo. Esta tipología, además, está determinada por la herencia de un sustrato islámico.

58 Tal vez por la presencia del arzobispo, sus villas no presentan parroquias numerosas, salvo en Brihuega o Talavera, y aquí ya conformada así cuando la recibe el arzobispo. No hay más que un templo, como Yepes, o dos como Alcalá de Henares.

${ }_{59}$ A veces se reproduce el esquema de iglesia y centro de mercado, donde aparecen los soportales, elemento característico y creación de la ciudad castellana bajomedieval, de fines del XIV y del xV (calle Mayor Alcalá de Henares, Brihuega, Yepes, Puente del Arzobispo, Torrelaguna). 


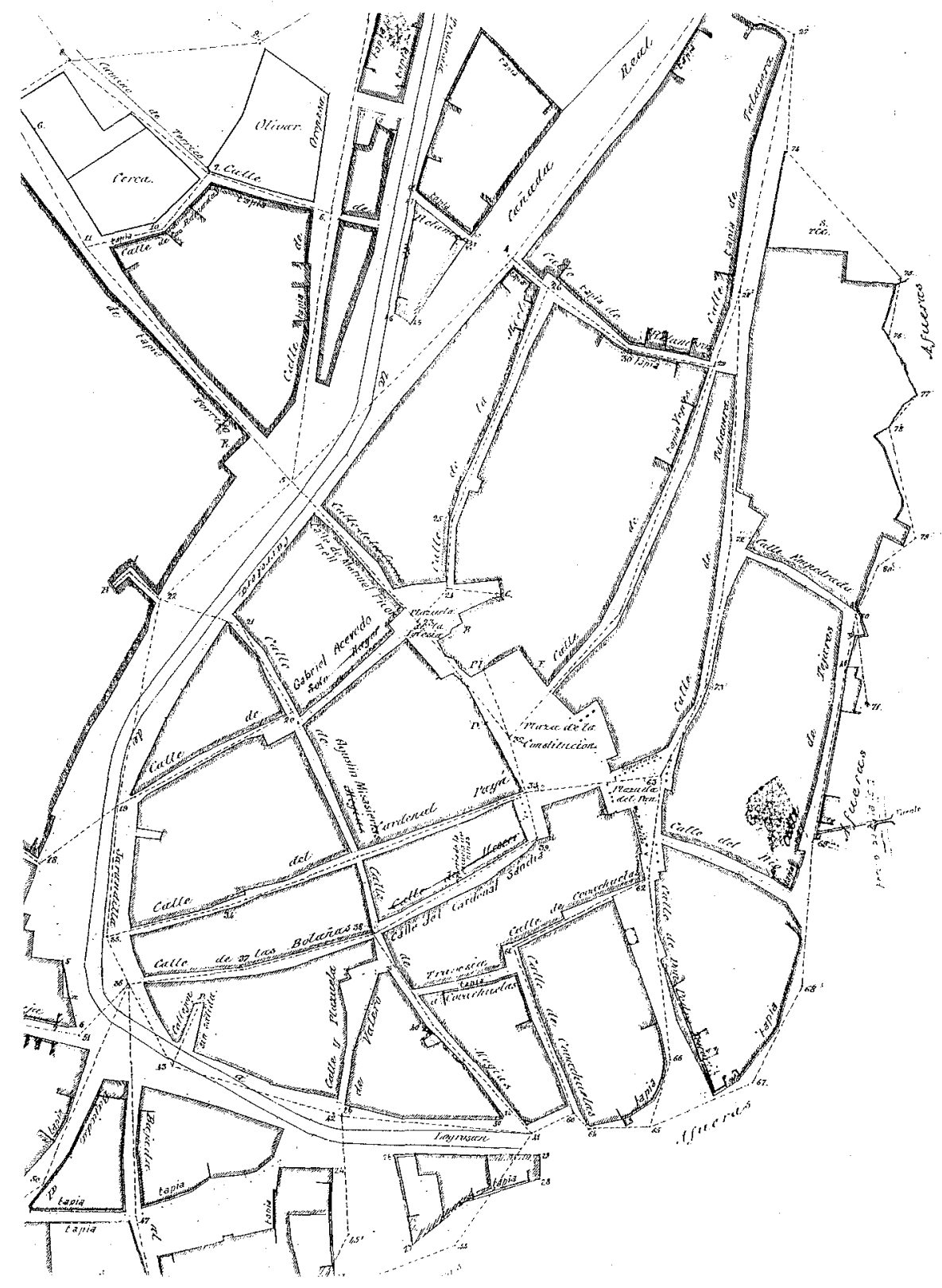

Fig. 11. IGN. S. XIX. Plano de Puente del Arzobispo. 
La cerca urbana define esta ciudad medieval, estableciendo el acotamiento espacial que contrapone la villa al resto del territorio. Estos rasgos son, por otra parte, identificativos del urbanismo cristiano peninsular. Al encontrarse en igual medida en los núcleos del arzobispo, permiten la aproximación a una de las facetas más desconocidas de la figura del primado de Toledo, la del señor medieval, propietario del mayor patrimonio inmueble de Castilla en la Edad Media. 